\title{
Research on Weakening Control of Asynchronous Motor with Load Based on Vector Control
}

\author{
Guomei Tang and Tao Huang \\ Wuhan University of Technology, Wuhan, China
}

\begin{abstract}
As for the induction motor with load needs to run in a large area, so speed regulation is an essential part of the current at a higher speed to prevent the voltage and current exceeds the rated value of the normal operation of the motor damage to the need for reasonable distribution, That is, the motor into the weak magnetic area in order to achieve the motor speed. Under the rotor flux orientation control, the current closed-loop control algorithm is realized based on the traditional 1 / wr flux-weakening control, and the algorithm is implemented in MATLAB. Meanwhile, the pid Parameter tuning, the results also show the effectiveness of the algorithm.
\end{abstract}

Keywords-vector control; asynchronous motor; field weakening speed; pid parameter tuning

\section{PREFACE}

At present, due to the increasingly widespread use of asynchronous motors, especially in the application of new energy vehicles. When the induction motor is running, in order to reach the requirement of high speed, the induction motor is affected by the supply voltage, and the current will also be influenced by the factors of the motor and the inverter. When the motor runs with load, its output torque The requirements will be relatively high, usually using some speed control method $^{[1]}$, this time is in the vector control method by reducing the flux, that is, the field weakening speed to make the motor voltage and current are subject to power supply and inverter limits In the case of high-speed output and torque stable output, although the re-vector control method is easy to achieve speed control, but how to make it still under load with a stable output is more difficult ${ }^{[2]}$.

In the traditional field-weakening speed control mode, it adjusts the speed according to the ratio of the base speed so as to control the flux decreasing with the increase of the speed ${ }^{[3]}$, but its current variation is slow to follow. The other method is to pass Set the closed-loop voltage control, the main is to detect the motor stator voltage exceeds its maximum limit voltage to regulate the excitation current, and thus the realization of weak magnetic speed control, but the algorithm design is more complex; there is a kind of motor parameters To calculate the best current value ${ }^{[4]}$, but a high degree of dependence on the motor, parameter measurement accuracy cannot be achieved, so there is no advantage in practical applications.

In the way of vector control, this paper introduces the torque current error based on the traditional flux-weakening speed control, and increases the current followability by controlling the excitation current to achieve the purpose of speed regulation. At the same time, taking into account the motor carrying load, PID parameters to achieve a stable torque output.

\section{INDUCTION MOTOR MATHEMATICAL MODEL}

\section{A. Induction Motor in dq Coordinate System Mathematical} Model

Based on the vector control of asynchronous motor dq twophase rotating coordinate system voltage equation is:

$$
\begin{aligned}
& u_{s d}=R_{s} i_{s d}-w_{h e}\left(1-L_{m}^{2} /\left(L_{s} L_{r}\right)\right) L_{s} i_{s q} \\
& u_{s q}=R_{s} i_{s q}+w_{h e} L_{s} i_{s q}
\end{aligned}
$$

The torque equation is:

$$
\begin{aligned}
& T_{e}=\frac{n_{p} L_{m}}{L_{r}} i_{s q} \varphi_{r} \\
& T_{e}=1.5 n_{P} \frac{L_{m}^{2}}{L_{r}} i_{s d} i_{s q}
\end{aligned}
$$

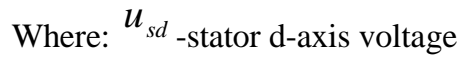

$u_{s q}$ - stator q-axis voltage

$i_{s d}$ - stator q-axis current

$i_{s q}$ - stator q-axis current

$W_{\text {he }}$ - Motor rotating field angular velocity

$R_{s}$ - Stator resistance

$L_{s}$ - Stator inductance

$L_{m}$ - Mutual inductance

$L_{r}$ - Rotor inductance 


$$
\begin{aligned}
& n_{p} \text {-Number of pole pairs } \\
& \varphi_{r} \text { - rotor flux vector }
\end{aligned}
$$

\section{B. Weak Magnetic Control Voltage and Current Conditions}

Under the maximum voltage limit of the inverter, the stator voltage under the operation of induction motor shall meet the following conditions:

$$
u_{s \max }=u_{d c / 1.732}
$$

The maximum voltage and current limit of the stator is:

$$
\begin{aligned}
& u_{s d}^{2}+u_{s q}^{2} \leq u_{s \max }^{2} \\
& i_{s d}^{2}+i_{s q}^{2} \leq i_{s \max }^{2}
\end{aligned}
$$

As the motor speed at high speed, the internal stator resistance voltage drop is small, negligible, according to (1) to simplify the voltage equation is:

$$
\begin{aligned}
& u_{s d}=-w_{h e}\left(1-L_{m}^{2} /\left(L_{s} L_{r}\right)\right) L_{s} i_{s q} \\
& u_{s q}=w_{h e} L_{s} i_{s q}
\end{aligned}
$$

Substituting (5) into (4) yields:

$$
\frac{i_{s d}^{2}}{\left(\frac{u_{s \max }}{w_{h e} L_{s}}\right)^{2}}+\frac{i_{s q}^{2}}{\left(\frac{u_{s \max }}{w_{h e} L_{s}\left(1-L_{m}^{2} /\left(L_{s} L_{m}\right)\right)}\right)^{2}} \leq 1
$$

It can be seen that the current limit represented by Eq. (6) is an ellipse, and the elliptic area decreases with the increase of rotational speed. Combining Eqs. (5) and (6), the current- (W1 $<$ w11 <w12):

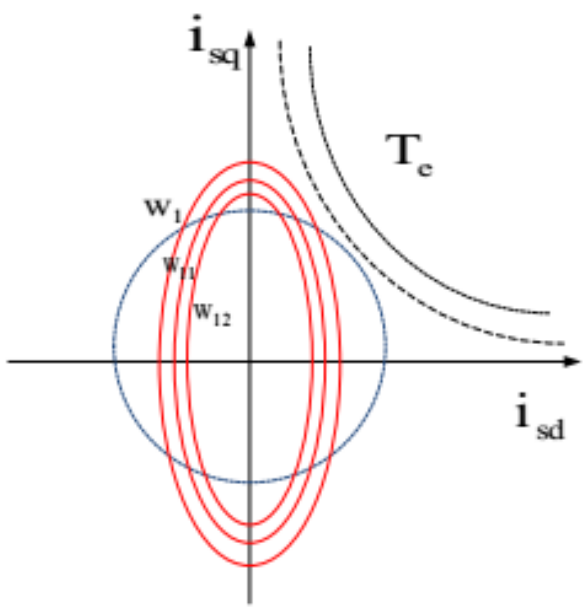

FIGURE I. VOLTAGE AND CURRENT LIMITS

As can be seen from the figure, as the speed increases the synchronous angular velocity decreases, the stator voltage is rising, the limiting part of the area is getting smaller and smaller, and inverter and motor overload determines the motor maximum current, regardless of the motor The speed of operation must be guaranteed in this limited part, so need to consider the excitation current processing, by controlling it to reduce the flux.

\section{FIELD WEAKENING SPEED CONTROL}

\section{A. Algorithm Analysis}

This is an improved traditional weak field control based on vector control ${ }^{[5]}$. The method is widely used, easy to control and easy to implement by algorithm. The control block diagram is shown in Figure II below:

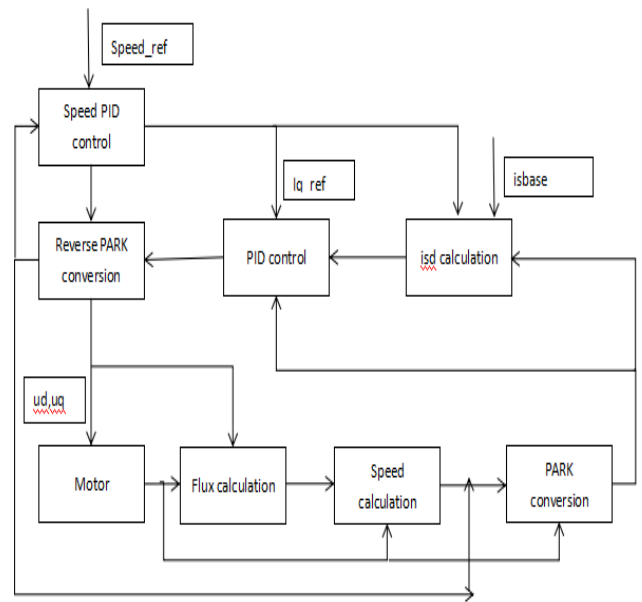

FIGURE II. WEAK MAGNETIC CONTROL BLOCK DIAGRAM

As shown in the above figure, the error of Iq is introduced into the calculation of Id, and the obtained value is used as the given value of the exciting current, which effectively improves the followability of the exciting current. 


\section{B. Simulation Results and Analysis}

In order to verify the correctness of the theory, the simulation and experimental motor parameters are:

Rs $=1.723$ - stator resistance $(\mathrm{ohm})$

$\mathrm{Rr}=2.011$ - rotor impedance $(\mathrm{ohm})$

$\mathrm{Ls}=(7.387+159.232) * 1 \mathrm{e}-03$ - Stator inductance $(\mathrm{H})$

$\mathrm{Lr}=(9.732+159.232) * 1 \mathrm{e}-03$ - rotor inductance $(\mathrm{H})$

$\mathrm{Lm}=159.232 * 1 \mathrm{e}-03$ - Excitation inductance $(\mathrm{H})$

$\mathrm{J}=0.001$ - rotor moment of inertia $(\mathrm{kg} \cdot \mathrm{m} \wedge 2)$

$\mathrm{B}=0.0001$ - damping coefficient (N.m.sec / rad)

$\mathrm{Ib}=5$ - phase current (amp)

$\mathrm{Vb}=320 /$ sqrt (3) - Phase Voltage (volt)

$\mathrm{Lb}=\mathrm{Lm} * \mathrm{Ib}-$ Flux (volt.sec $/ \mathrm{rad})$

$\mathrm{Tb}=3 * \mathrm{Vb} * \mathrm{Ib} / 2 * \mathrm{np} / 2 * \mathrm{pi} * 60$ - Torque (N.m)
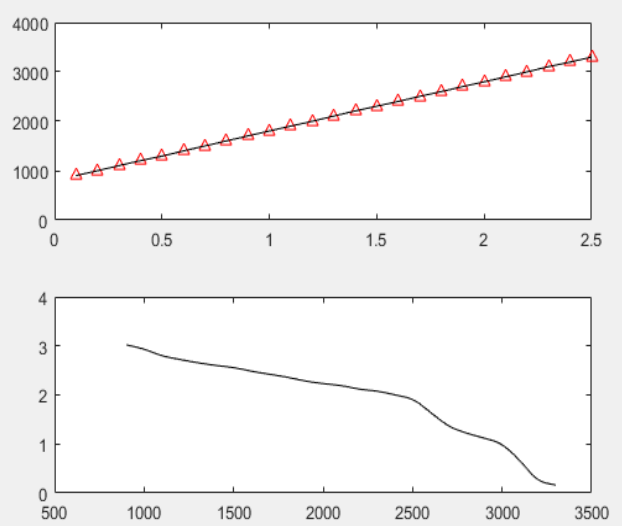

FIGURE III. TIME-SPEED (RAD / SEC) SPEED - EXCITATION CURRENT (AMP)

It can be seen that as the speed increases, and the control error is good and basically reached the ideal given value, the excitation current is constantly decreasing, indicating the effectiveness of the method and the algorithm is achievable.

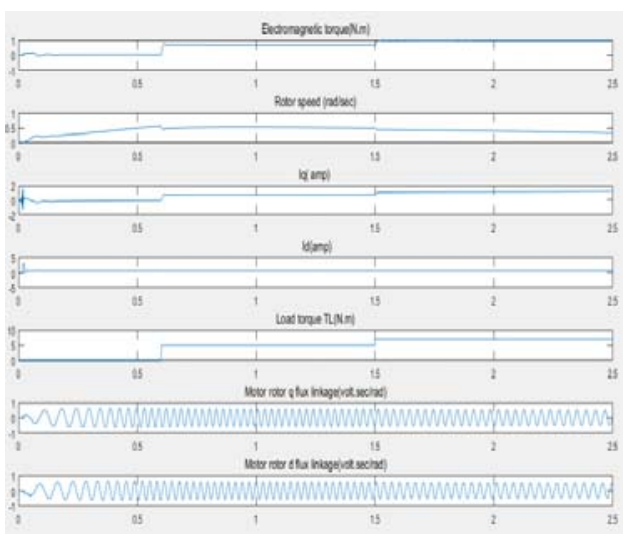

FIGURE IV. TIME - PARAMETER VALUE
It can be observed from the figure that the speed reaches a given value (0.5), and there is a certain error. By adjusting the PID parameters, the stable output of the speed and torque can be achieved. The specific observation values are as follows:

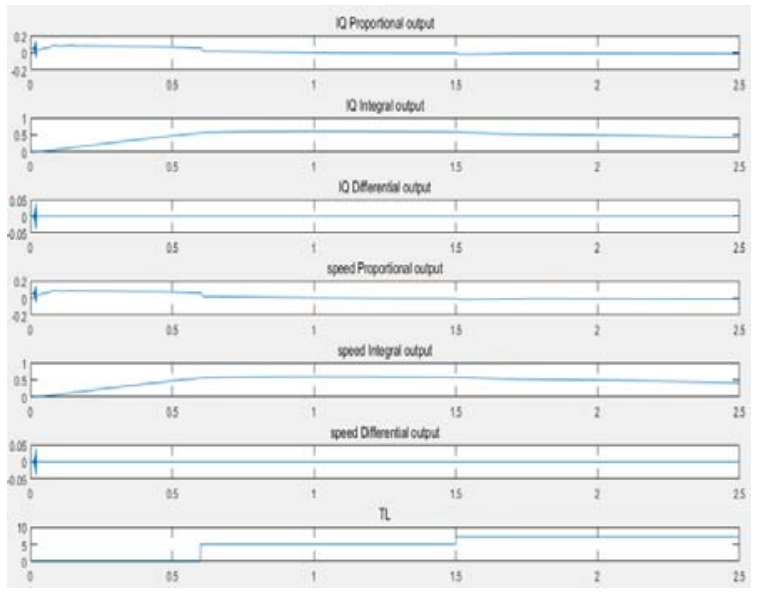

FIGURE V. TIME-PID PARAMETER TUNING

The basic method of adjustment process has the following points:

First, given a smaller load, and a smaller speed, the initial value of the PID parameter can be determined by fine tuning the output to be stable.

Increase the load, or given a changing load, by observing whether the output value of each PID is stable to achieve speed output stability;

When the load value is too large, the accuracy of the fluxweakening speed regulation will be relatively high. At this moment, the PID parameters must be adjusted slightly.
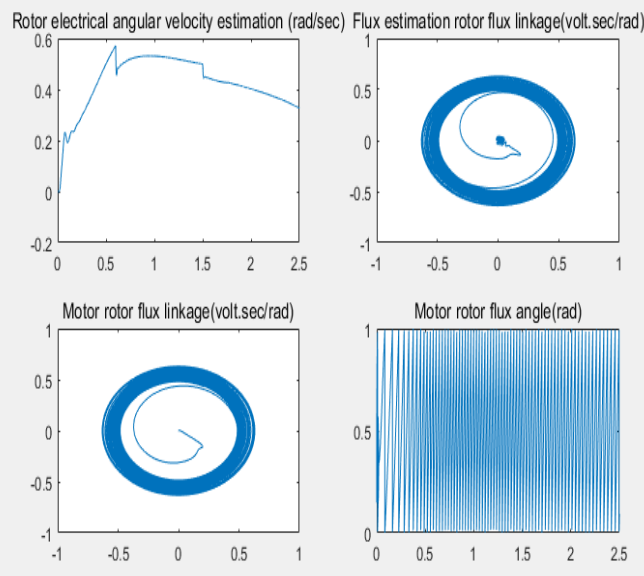

FIGURE VI. TIME-FLUX

The figure can be seen in the motor speed, torque has reached a stable flux will reach stability. 


\section{CONCLUSION}

In this paper, the speed control algorithm of the closed-loop control of the excitation current is realized based on the traditional weak magnetic speed control under the vector control, and the PID parameters are adjusted to achieve the stable output. Validity and feasibility have been verified, provide a reference for the work carried out later, has a certain precedence, the algorithm design is relatively simple to determine its portability.

\section{REFERENCE}

[1] S-H Kim and S-K Sul. Maximum torque production control of an induction machine in the field weakening region [J]. IEEE Transactions on Industry Applications. 1995.31 (4): 787-794

[2] Dou Juzhen, Xin Minghua, Du Zhiming, weakening control method of asynchronous motor for electric vehicle based on vector control [J]. Motor and Control Applications, 2009,36 (5): 25-27

[3] HUANG M S, LIAW C M. Transient perfoemance, improovement control for IFO induction motor drive in field-weakening region [J]. Proceedings-Electric Power Applications. 2003,150 (5): 521-530

[4] Fan Ye, Chen Yiheng, Wang Jianhua, induction motor optimal current sharing method of weak magnetic control [j]. Industry and Mine Automation, 2013,39 (11): 71-75

[5] Li Ye-song, Lei Li, Research on field weakening of induction motor based on rotor field orientation [J]. Power Electronics Technology, 2007, 41 (5): 34-35. 